\title{
Goods Segregation Robot for Industry
}

\author{
K.Bhavana ${ }^{1}$, B.Lalitha ${ }^{2}$, T. Srinivasa Rao ${ }^{3}$, Dr.M.V.Ramesh ${ }^{4}$ \\ ${ }^{1}$ Prasad V Potluri Siddhartha Institute of Technology, Kanuru,Vijayawada, Andhra Pradesh, India \\ ${ }^{1}$ Department of Electrical and Electronics Engineering, bhavana.kadiyala1@ gmail.com \\ ${ }^{2}$ Prasad V Potluri Siddhartha Institute of Technology, Kanuru,Vijayawada, Andhra Pradesh, India \\ ${ }^{2}$ Department of Electrical and Electronics Engineering, lalithaurz@ gmail.com \\ ${ }^{3}$ Prasad V Potluri Siddhartha Institute of Technology, Kanuru,Vijayawada, Andhra Pradesh, India \\ ${ }^{3}$ Department of Electrical and Electronics Engineering,srinuthumati@ gmail.com \\ ${ }^{4}$ Prasad V Potluri Siddhartha Institute of Technology, Kanuru,Vijayawada, Andhra Pradesh, India \\ ${ }^{4}$ Department of Electrical and Electronics Engineering, vrmaddukuri@ gmail.com
}

\begin{abstract}
The adjustments in assembling advances in the enterprises which are used in expanding efficiency. The term Industry 4.0 shows the the fourth mechanical insurgency[4] that is characterized as another degree of association and authority over the whole worth chain of the existence pattern of items; it is equipped towards progressively individualized client necessities.

In major Industries, the lack of skilled and knowledgeable staff for segregation of goods is increasing day by day. To overcome this problem a robot is proposed for segregation of goods to their respective locations. Here the robot will scan the $\mathrm{QR}$ code by image processing and segregate goods to their respective sections. Uses of robotization will definitely bring about ideal usage of machine and labor. This robot is interfaced with NI myRIO. In this venture, robot is intended to work naturally according to checked QR code information.
\end{abstract}

Key words: NimyRIO, Motor drivers, robot, ackreman's forklift mechanism.

\section{INTRODUCTION}

To defeat this issue a robot is proposed for isolation of products to their individual areas. Here the robot will examine the QR code by picture handling and isolate products to their separate segments. Mechanization is definitely bring about ideal usage of machine and labor. This robot is interfaced with NI my RIO. In this undertaking, robot is intended to work naturally according to examined QR code information.

\section{BLOCK DIAGRAM DESCRIPTION}

\subsection{SYSTEM BLOCK DIAGRAM}

The block diagram shown in Figure 1 for both the Line follower and the autonomous forklift are realized after determining the necessary components. The block diagrams provide clear picture of the overall system.

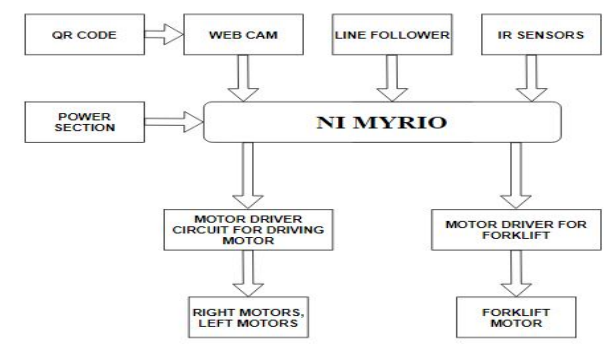

Figure 1: Block diagram

The information on the QR code is collected by using web camera. Web camera passing the necessary information to the NImyrio processer to process the obtained data from the QR code. Based on the collected information NImyrio starts the processing and sending the necessary information to the ultrasonic sensor. The ultrasonic sensor performs two operations to the detecting, sense the object and also measures the distance between the goods and forklift. After completion of the ultrasonic operation the fork lift motor is driven by using forklift motor driver. With help of forklift technique the pallet goods are lifted and IR sensors are used to check the position of the pallet goods. The operation of the base motor is to perform forward, left and right motions driven by motor driving circuit. And then the robot performs its operation by line follower following the line. Here the robot moves and places the pallet goods from one place to another place. The operations of web camera, ultrasonic sensor, IR sensor, motion of the base motors, forklift motors, 
K.Bhavana et al., International Journal of Emerging Trends in Engineering Research, 8(9), September 2020, 5828 - 5831

motor driving circuit is incorporated or programmed in NI MYRIO.

\subsection{BLOCK DESCRIPTION}

\section{QR CODE}

A QR code is one type of barcode which contains a matrix of dots. Here, the QR code is incorporated with the pallet goods segregation destination information.

\section{WEB CAMERA}

The Web camera scans the QR code

\section{ULTRASONIC SENSOR}

The Ultrasonic sensor is used to sense the object (i.e. pallet goods). At a time it can also measure the distance robot forks and the object[3].

\section{IR SENSOR}

An infrared senses the characteristics of its surroundings[3] NI MYRIO

NIMYRIO is a real-time embedded evaluation board made by National Instruments which is used to develop applications that utilize its onboard FPGA and microprocessor. It uses LabVIEW. It can provides educators with an embedded, WiFi-enabled solution to deliver an engaging approach to learning controls, investigating mechatronics, and designing imaginative capstone projects. Use online, interactive teaching resources to integrate myRIO into classes and projects. Here, the operation of myrio is to run the line follower, IR sensor, ultrasonic, motor drivers and motor corresponding to the LabVIEW code.

\section{MOTOR}

The yield of the engine drivers[8] is contribution of the Johnson engines. The Johnson Electric DC engine arrangement is the business benchmark for smaller scale engine driven activation. This wide scope of engine stages can be specially designed to meet the force, size, productivity and life prerequisites of the client's application

\section{LINE FOLLOWER}

Line follower is an assembled robot which follows either black line in white are or white line in black area. Robot must be able to detect a particular line and keep following it. These robots are used as automated equipment carriers in industries replacing traditional conveyer belts. Automobile applications: These robots can also be used as automatic cars running on roads with embedded magnets.

\subsection{BASE STRUCTURE}

The base structure as shown in Figure 2 of our INDUSTRIAL AUTONOMOUS ROBOT FOR PALLET GOODS[1] is designed by using $2 \mathrm{~mm}$ gauge steel sheet having dimensions of $56.5 * 30.6 * 4.5 \mathrm{~cm}$. And get foundered according to our required design specification to carry our robot weight equally. Movement to our robot we are implementing DIFFERENTIALSTEERING mechanism by utilizing 4 no's, $60 \mathrm{rpm}, 20 \mathrm{~kg} / \mathrm{cm}$ torque, Permanent magnet direct current (PMDC) Johnson motors to drive our robot, also to carry and place the pallet at respective destination safely and smoothly without any damage to the goods which are placed on the pallet[2].

At the fore end of our robot we are placing WEBCAMERA to scan the $\mathbf{Q R}$ code on the pallet to give necessary information to the NI MYRIO processer and $\mathbf{5}$ individual Infrared Ray (IR) sensors connected in series to our base plate perform the LINE FOLLOWER operation efficiently for navigating the destination precisely. At the rare end of the robot we are using the 2 no's $12 \mathrm{~V}, 7.5 \mathrm{Amps}$, LEAD ACID Batteries as the counter weight to our robot for balancing the robot to avoid tilting and sliding of the robots whenever the robot picks up the pallet.

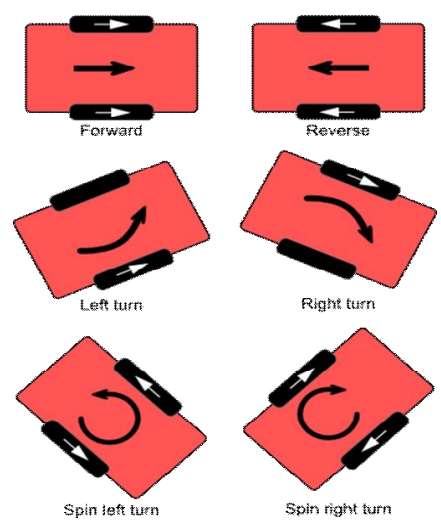

Figure 2: Direction of differential steering

Ackerman Steering:

Advantages of Ackermansteering:

1. Easilyprogrammable.

2. Most appropriate for high speedrobots.

- Disadvantages of Ackermansteering:

- 1. Unable to spin on its ownaxis.

- 2. Increases wear on wheels.

- 3. Difficult toimplement.

\section{SOFTWARE REQUIREMENTS}

\section{LABVIEW:}

LABVIEW is system engineering software for applications that require test, measurement, and control with rapid access to hardware and data insights. 
License: Proprietary

Preview release: NXG 3.0 Beta1

Developed by: National Instruments

Operating system: Cross-platform: Windows, Linux

Written in : $\mathrm{C}++$, .NET Framework

\section{WORKING}

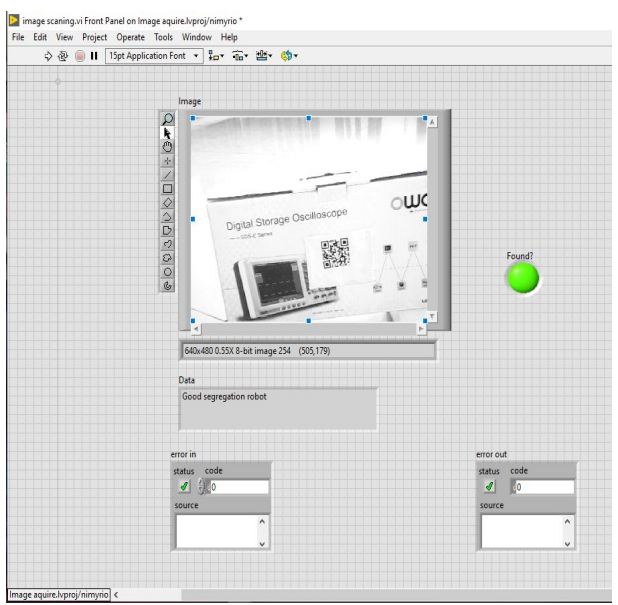

Figure 3: QR Code front panel

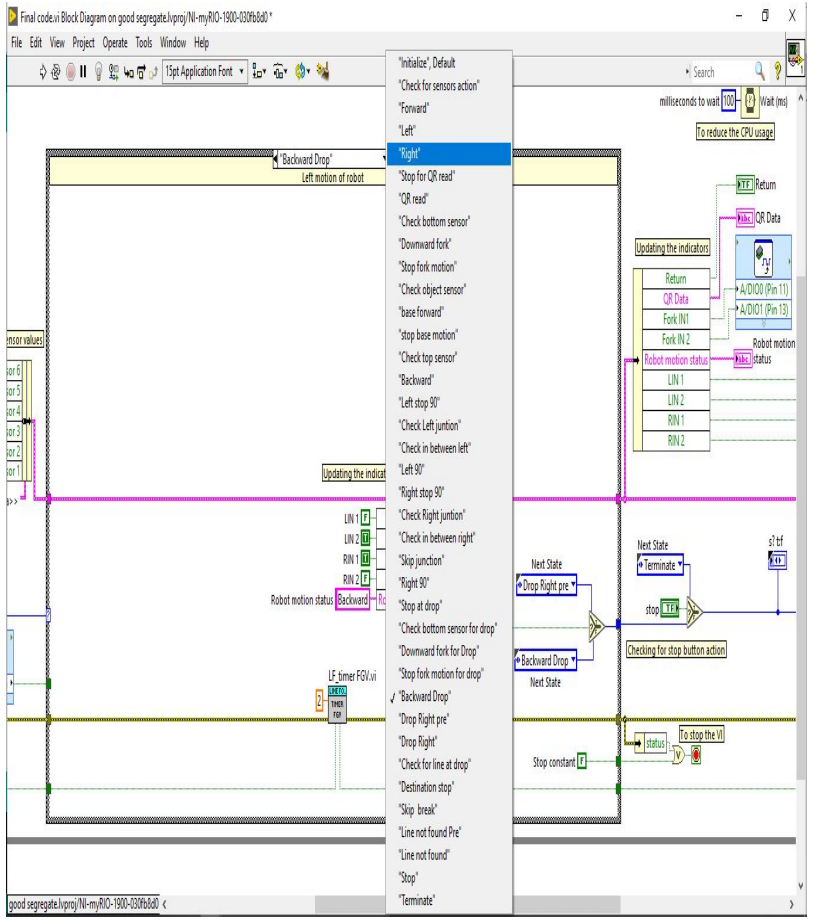

Figure 4: Block diagram of main code

The goods segregation robot operates on autonomous guided vehicles. The autonomous robots performs major role in industries.

The robot working is mainly based on QR code and forklift mechanism. The QR code plays a major role in this project,it stores the destination data in the form of bar code. The operation of QR code according to flow chart is explained as follows.

When the QR code as shown in figure 3 and figure 4 , the scanning operation starts the vision acquisition comes into picture from NImyRIO. The vision acquisition is one of the pallet in NImyRIO, which is the vision development module. USB web camera is used to capture the image from the QR code. After, then the vision acquisition gives the command as read $\mathrm{QR}$ code. The data in the $\mathrm{QR}$ code is collected and displayed in the front panel of NImyRIO. Whenever data is displayed the LED glowsand ends its operation and goes to its initial state and the loop is iterated. We use forklift mechanism to carry the goods to their respective places. Forklift mechanism runs on electric motor. The electric motor gives the motion to the forklift vehicle like forward, backward, left turn, right turn and pallet controlling up and down motion.

When the robot reads the $\mathrm{QR}$ data, the robot will check for the bottom sensor activation. If bottom sensor is inactive, then the forklift moves downwards. When the bottom sensor gets activated, then the forklift stops its motion and the robot will check for object sensor activation. If object sensor is inactive then the robot will move forward. When the fork gets closer to the box the object sensor gets active. If the object sensor gets activated, the fork lift[4] moves upwards. Because of this action the box is lifted from the bottom. The robot will check for the top sensor activation. If it is activated then the forklift stops it motion. Then the robot move backwards for three seconds and then it will make right turn and check for the line. If the line is detected, it follows the line as per line follower code. If robot detects any junction in between, then it checks the junction with QR code data[5]. If both data gets matched then it will perform the turn (left or right) corresponding to the $\mathrm{QR}$ code data. Then it follows the line and checks for destination. If robot reaches the destination then the robot stops its motion. Next the robot will check for the bottom sensor activation.

If bottom sensor is still inactive, then the forklift moves downwards. When the bottom sensor gets activated, the forklift stops its motion. Then the robot will move backward for three seconds and then make right turn for checking the line. If the line is found then the robot follows the line and reaches the store. This process continues for the next box to be lifted. The front view of the model is shown in figure 5. 


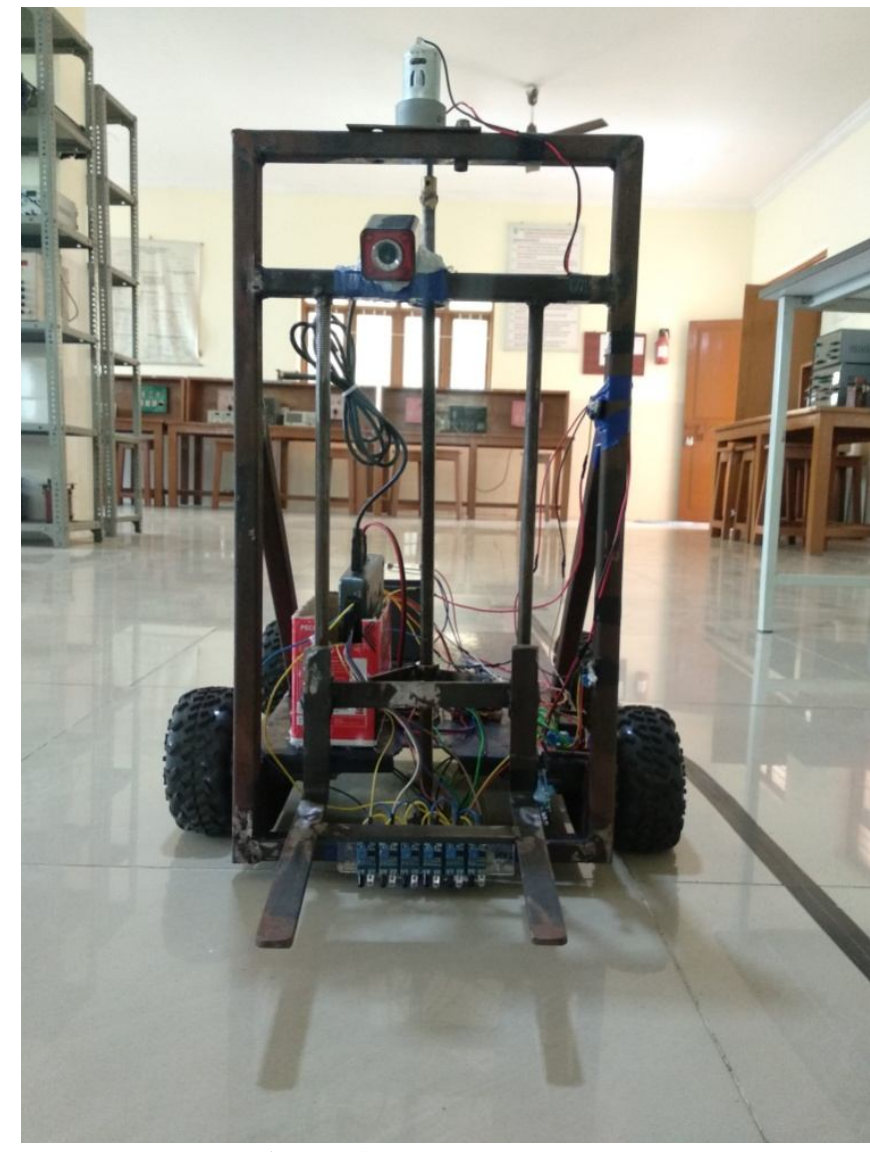

Figure 5: Front view

\section{CONCLUSION}

The aim of this project is to design and implement a system capable of transporting the loads and loading them into specific trailers by observing a loading pattern. Since the system is meant to operate in an environment without human effort, this design includes the necessary features to ensure the safety of any person who may be in the proximity of the forklift. To meet this, a system comprising of two sub-systems mainly a NImyRIO, forklift and line follower were investigated in the conceptual design. The electronic design forms the major part of this project. As there is a problem of lack of output ports in microcontroller and arduino.this problem was solved by the use of a NImyRIO. The latter was used to control the direction of rotation of the motors, fork lifting motor and IR sensor. NIMYRIO is heart of this project, it takes input as Web camera, IR sensors, line follower and the outputs as motor driver modules for base motors and forklift motor. The web camera scan the QR code and give the destination place name to NImyRIO. Line follower maps the root and is given to NImyRIO, then follows the path of IR sensor and senses the black on white surface which gives the sense signal as input to NImyRIO. In NImyRIO the processor processes the signals and drives the motors of base design and forklift with the help of motor driver module based on the inputs of web camera, line follower and IR sensor.
The software for forklift, QR code and motor driver circuit in order to control its directions of motors is done by using Laboratory Virtual Instrument Engineering Workbench (LabVIEW).

\section{REFERENCES}

1. Grover, M. (2001) Automation, Production Systems, and Computer Integrated Manufacturing, 2nd ed. New Jersey: Prentice Hall, p.282-283.

2. JBT Corporation (2011) AGV safety, [online] Available at:

3. http://www.jbtcagv.com/en/knowledge/safety

4. IIRsensorshttps://www.elprocus.com/infrared-ir-sensor-circuit -and-working/

5. Wikimedia (2011) Forklift Truck, [online] Available at: http://www.wikimheda.org/wiki/Forklift_truck

6. SDI (2011) Carton and box sorter machine, [online] Available at: http://www.sdipromech.com/index.php/sorting_syst ems/carton_box_sorting\% 20machine

7. Keyence Corporation (2011) Card Box Conveyors, [online]. Available at: http://www.keyence.co.uk/products/barcode/barcode /bl700/bl700_applications_1_1.php

8. S-Elektronik (2011) E-Jet, [online] Available at: http://www.selektronik.de/77-0-E-JET+english.html

9. Drivercircuithttps://patents.google.com/patent/US6542012

10. NIMyRIOhttps://www.theengineeringprojects.com/2017/08/in troduction-to-myrio.html

11. The effect of additive on pertalite to increase motor cycle fuel efficiency,ijeter 04882020 .

12. An Efficient Energy Saving Scheme Through Sorting Technique for Wireless Sensor Network, ijeter 38882020 .

13. "Evaluation of Reconfigurable Implementation of Digital controlled

Induction Motor Drives", IEE International Conference Emerging Technologies in Electrical Systems PEITSICON2005-Kolkata. 